\title{
Cost of inaction on sugar-sweetened beverage consumption: implications for obesity in South Africa
}

\author{
Aviva Tugendhaft ${ }^{1}$, Mercy Manyema ${ }^{1}$, Lennert J Veerman ${ }^{2}$, Lumbwe Chola ${ }^{1}$, \\ Demetre Labadarios ${ }^{3}$ and Karen J Hofman ${ }^{1, *}$ \\ 'PRICELESS SA-MRC/Wits Rural Public Health and Health Transitions Research Unit (Agincourt), School of Public \\ Health, Faculty of Health Sciences, University of the Witwatersrand, Office 231, 2nd floor, Wits Education Campus, \\ 27 St Andrews Road, Parktown, Johannesburg, South Africa 2193: ${ }^{2}$ School of Population Health, University of \\ Queensland, Brisbane, QLD, Australia: ${ }^{3}$ Population Health, Health Systems and Innovation, Human Sciences \\ Research Council, Cape Town, South Africa
}

Submitted 20 January 2015: Final revision received 11 September 2015: Accepted 23 September 2015: First published online 23 0ctober 2015

\begin{abstract}
Objective: To estimate the effect of increased sugar-sweetened beverage (SSB) consumption on future adult obesity prevalence in South Africa in the absence of preventive measures.

Design: A model was constructed to simulate the effect of a $2.4 \%$ annual increase in SSB consumption on obesity prevalence. The model computed the change in energy intake assuming a compounding increase in SSB consumption. The population distribution of BMI by age and sex was modelled by fitting measured data from the 2012 South African National Income Dynamics Survey to the log-normal distribution and shifting the mean values.

Setting: Over the past decade the prevalence of obesity and related noncommunicable diseases has increased in South Africa, as have the sales and availability of SSB. Soft drink sales in South Africa are projected to grow between 2012 and 2017 at an annual compounded growth rate of $2.4 \%$ in the absence of preventive measures to curb consumption.

Results: A $2.4 \%$ annual growth in SSB sales alongside population growth and ageing will result in an additional 1287000 obese adults in South Africa by 2017, $22 \%$ of which will be due to increased SSB consumption.

Conclusions: In order to meet the South African target of reducing the number of people who are obese and/or overweight by $10 \%$ by 2020 , the country cannot afford to delay implementing effective population-wide interventions. In the face of plans to increase growth of SSB, the country will soon face even greater challenges in overcoming obesity and related non-communicable diseases.
\end{abstract}

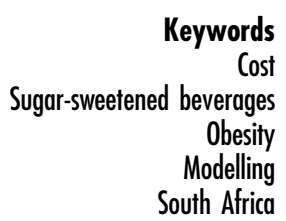

South Africa has the highest prevalence of obesity in sub-Saharan Africa. In the past decade (2003-2012) this has increased among men by $2 \%$ from 9 to $11 \%$ and among women by $12 \%$ from 27 to $39 \%{ }^{(1,2)}$. Simultaneously, the sales and availability of sugar-sweetened beverages (SSB) have increased alongside all categories of packaged and fast foods ${ }^{(3)}$. Excess sugar consumption is associated with weight gain and an increased risk for noncommunicable diseases (NCD) including CVD, type 2 diabetes and cancer, which account for $27 \%$ of all deaths in the country ${ }^{(4-7)}$. NCD place significant financial strain on families and on the country. Moderate obesity (BMI = $30-35 \mathrm{~kg} / \mathrm{m}^{2}$ ) is associated with an $11 \%$ increase in health-care costs and severe obesity $\left(\mathrm{BMI}>35 \mathrm{~kg} / \mathrm{m}^{2}\right)$ with a $23 \%$ increase $^{(8)}$. Obesity and its associated diseases and ailments also negatively impact the workplace by increasing turnover, absenteeism and worker compensation claims, and decreasing productivity ${ }^{(9)}$.

While all foods high in sugar have a harmful effect on the body, liquid sugar in the form of SSB is rich in energy, but poor in other nutritional content, and has a negligible impact on satiety ${ }^{(10)}$. Although consumption of SSB is not the only cause of obesity, it is strongly linked to increased energy intake ${ }^{(11)}$ and weight gain in both adults and children due to the high sugar content in these drinks. A $330 \mathrm{ml}$ can of carbonated soft drink in South Africa contains an average of $40 \mathrm{~g}$ of sugar and the same size of sweetened fruit juice approximately $45 \mathrm{~g}$ of sugar. Drinking a single SSB daily increases the likelihood of being overweight by $27 \%$ for adults and $55 \%$ for children ${ }^{(12,13)}$. 
Consuming one or two SSB daily increases the risk of developing type 2 diabetes by $25 \%^{(14)}$.

As part of the nutrition transition in South Africa it is increasingly difficult to make healthy choices, as energydense foods have become more affordable and widely available. This has seen the increase in availability of and access to SSB in lower income groups and the commensurate growth of this segment of consumers. Those in living standard measure (LSM) 1-4 (the four lowest socioeconomic status (SES) groups) comprise almost 7 million adults who earn less than R3500 (\$US 333) per month ${ }^{(15)}$. Access to unhealthy but affordable foods and beverages in this demographic group has increased over the last few years due to expansion of supermarkets into informal urban settlements and rural areas. This has resulted in a simultaneous double burden of malnutrition characterised by both overnutrition (overweight, obesity) and undernutrition (underweight, wasting, stunting). Furthermore, while approximately $40 \%$ of South Africans now consume the recommended daily amount of energy, the food sources for this energy are significantly low in nutrients, resulting in individuals who are often overweight from consumption of high amounts of energy but also undernourished from low levels of nutrients ${ }^{(2)}$.

Significant resources are invested into marketing energy-dense products partially because they are cheap to produce and highly palatable ${ }^{(16)}$. New technologies have enabled companies to gather data on consumer preferences, which in turn are used to market products aggressively based on demographics. Products are often placed strategically in formal and informal convenience stores ('spaza' shops) to ensure the most profitable ones are at eye level and easily accessible ${ }^{(16)}$.

A single beverage company accounts for approximately $60 \%$ of the off-trade (excludes hotels, restaurants and registered bars) soft drinks market in South Africa and was rated as the overall favourite brand in the country in $2013^{(17)}$. In 2012 South Africans consumed an average of 285 Coca-Cola products per person, a $56 \%$ increase from 2002 , placing the country tenth in the world for consumption of these products ${ }^{(18,19)}$. This has been accomplished through the use of local advertising campaigns linking the brand to South Africans' aspirations and passions as well as the increase in product availability ${ }^{(20)}$. It has been shown that preference for food products is often shaped not only by taste but largely by brand image ${ }^{(16)}$.

The UN high-level NCD summit held in 2011 recommended that the 'best buys' for addressing obesity-related NCD included large-scale prevention interventions outside the health-care infrastructure ${ }^{(21)}$. The South African National Department of Health's National Strategic Plan for the Prevention and Control of Non-Communicable Disease 2013-2017 has listed fiscal policy as one cost-effective 'best buy' to prevent obesity and has set a target of reducing the number of people who are obese and/or overweight by $10 \%$ by $2020^{(6)}$. In line with these plans, the South African
Minister of Health recently called for regulations on foods high in sugar ${ }^{(22)}$.

Demands to implement fiscal measures to reduce SSB consumption are growing in several other countries, including India, Ireland, the UK and Australia ${ }^{(23,24)}$. In October 2013 Mexico passed a tax on SSB and junk food, followed by Chile in January 2015, and Hungary and France also have newly introduced SSB taxes ${ }^{(25-27)}$. Berkeley, California has recently become the first city in the USA to pass an SSB $\operatorname{tax}^{(28)}$. Since the implementation of the SSB tax in Mexico in January 2014, SSB sales in the first quarter of 2014 compared with those in the first quarter of 2013 dropped by $10 \%$ while bottled water sales increased by $13 \%{ }^{(29)}$.

A South African modelling study estimated that a $20 \%$ SSB tax would reduce obesity by $3.8 \%$ in men and $2.4 \%$ in women. This would result in a reduction of the number of obese adults by over $220000(2 \cdot 8 \%)^{(30)}$. This type of fiscal intervention, alongside other preventive measures, could alleviate the growing obesity and related NCD burden on the health system. However, without such interventions SSB consumption will continue to grow and the future impact of obesity will be difficult to curtail. According to Euromonitor International, a global market intelligence firm providing market data and analysis, sales of soft drinks in South Africa grew by $14.9 \%$ between 2007 and 2012 , and are projected to grow by $12 \cdot 8 \%$ over the five years between 2012 and 2017 at an annual compounded growth rate of $2 \cdot 4 \%{ }^{(31)}$. The aim of the present analysis was to determine the impact of increased SSB consumption on future obesity prevalence in South Africa in the absence of any preventive measures.

\section{Methods}

\section{Overview}

We constructed a mathematical simulation model to estimate the effect of an annual increase in SSB consumption on the prevalence of obesity based on the $2.4 \%$ industry growth rate projected by Euromonitor International for 2013-2017.

The model computes the counterfactual change in energy intake assuming a compounding increase in SSB consumption. Published equations linking energy intake to body weight were used to estimate changes in BMI and obesity ${ }^{(32)}$. The model was implemented in Microsoft ${ }^{\circledR}$ Excel (2010). The baseline year was 2012. Figure 1 presents the proposed conceptual framework for the effect of the growth in the SSB market.

\section{Data}

Baseline consumption

An SSB was defined as a non-alcoholic drink with added sugar and comprised carbonated and non-carbonated 


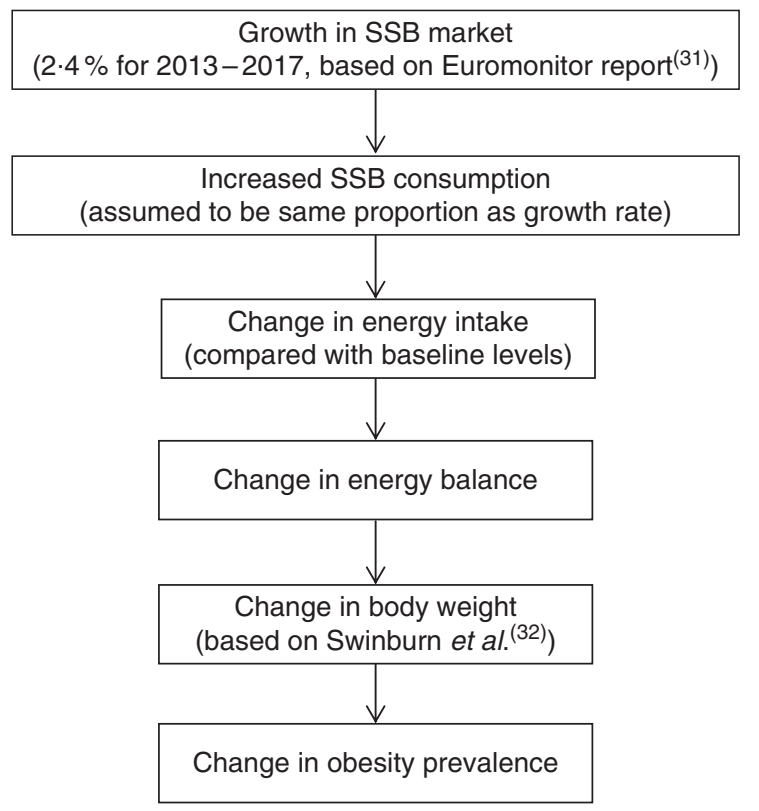

Fig. 1 Conceptual framework of the effect of the projected growth in the SSB market in South Africa (SSB, sugarsweetened beverages)

sweetened drinks, sweetened fruit juices and squash concentrates based on data available from the South African National Health and Nutrition Examination Survey (SANHANES-1). A broader definition of SSB includes, in addition to the above, sports and energy drinks, ready-todrink tea and coffee, flavoured milks and non-sweetened fruit juices. These were not included in our definition because data were not available from SANHANES-1. Data from SANHANES-1 were used to estimate SSB consumption in adults aged 15 years and above ${ }^{(2)}$. The SANHANES-1 is a baseline cross-sectional survey of the SANHANES series. Multi-stage disproportionate, stratified cluster sampling was used to select the study population and all individuals residing at the selected households were eligible to participate. Questionnaire-based data were obtained through interviews in combination with some health measurements.

The participants were asked how frequently they consumed SSB in the last week with response options of 'none', 'every day', 'one to three times last week' and 'four to six times last week'. We assumed one serving to be $330 \mathrm{ml}$, the size of a can of carbonated soft drink, and that one serving was consumed each time. The average consumption for the category was considered the midpoint of each frequency of consumption category.

\section{Rate of change of consumption}

Based on the 2013 Euromonitor report, the soft drink market, including all categories of SSB, in South Africa is projected to increase by $2 \cdot 4 \%$ per year up to $2017^{(31)}$. We assumed that SSB consumption would increase by $2.4 \%$ for males and females and across all age groups.
Prevalence of overweight and obesity in South Africa Anonymised public release data sets of wave 3 version 1 of the National Income Dynamics Study (NIDS) provided data for BMI estimates ${ }^{(33)}$. NIDS is South Africa's first national panel study and was implemented by the Southern Africa Labour and Development Research Unit based at the University of Cape Town's School of Economics. A total of 28255 individuals in 7305 households were recruited in the base wave in $2008^{(34)}$. Waves 2 and 3 were conducted in 2010/2011 and 2012, respectively ${ }^{(35,36)}$.

Our analysis included adult men and women aged 15 years and above with a valid height and weight measurement. We cleaned and coded the data in the statistical software package STATA version $12 \cdot 1$ (2011). Design effect was accounted for by using the STATA svyset command. BMI was computed as weight in kilograms divided by the square of height in metres. BMI values that were excluded from the analysis included those falling below and above the 1st and 99th percentiles, respectively. Data were fitted to the log-normal distribution in Microsoft Excel (2010) using the least-squares method. Polynomial functions were used to fit the means and standard deviations across age groups, separately for men and women. The fitting procedure and comparison of the lognormal distribution to the gamma distribution have been previously described ${ }^{(30)}$.

\section{Population estimates}

The 2012 to 2017 population estimates by sex and 5-year age groups were obtained from Statistics South Africa ${ }^{(37)}$.

\section{Modelling}

Following the steps presented in Fig. 1, we implemented the modelling as follows.

\section{Change in sugar-sweetened beverage consumption}

Using the Euromonitor $2.4 \%$ projected annual increase in SSB sales, the model was run twice for each year: (i) assuming $2.4 \%$ consumption growth; and (ii) assuming $0 \%$ consumption growth. Both scenarios accounted for population growth as forecast by Statistics South Africa.

\section{Change in energy intake}

The percentage change in energy intake from SSB was assumed to be the same as the percentage change in volume of SSB consumed. We used an average energy density estimate of $1800 \mathrm{~kJ} /$ litre (average of Coca-Cola $\mathrm{SSB}$ ) to convert the change in volume consumed to change in energy intake. We used Coca-Cola because it accounts for approximately $60 \%$ of the off-trade soft drinks market in South Africa according to the SABMiller Quarterly Divisional Seminar Series, South Africa ${ }^{(18)}$. In addition, personal communicator, Dr Celeste Naude, at the Centre for Evidence-based Health Care, Stellenbosch University, calculated the mean energy density for an SSB 
to be 188 (sD 40) kJ/100 ml using energy density values of a sample of ninety carbonated drinks, sports drinks, concentrates, iced teas and sweetened fruit juices obtained from the South African Medical Research Council Food Data System ${ }^{(38)}$ and nutrition information provided on beverage labels. In our model energy intake from other types of drinks other than the SSB defined above was not accounted for.

\section{Change in BMI}

We estimated the change in body mass using equations published by Swinburn et al., which state that an increase in daily energy intake of $94(95 \%$ CI $88 \cdot 2,99 \cdot 8) \mathrm{kJ} / \mathrm{d}$ is associated with a change in body weight of $1 \mathrm{~kg}$ in equilibrium for adults ${ }^{(32)}$. The change in average body mass was converted to change in average BMI by applying average height estimates from NIDS wave $3^{(33)}$ for each age group.

\section{Change in obesity prevalence}

Rose and Day's theorem that the mean predicts the number of deviant individuals was used to estimate the prevalence of overweight and obesity from the mean BMI for each age group and sex ${ }^{(39)}$. The difference in obesity prevalence between the model which assumed $2.4 \%$ consumption growth and that assuming $0 \%$ consumption growth was taken to be the increase in obesity due only to the projected increased SSB consumption.

\section{Confidence intervals}

Confidence intervals were obtained through Monte Carlo simulation using the Ersatz program (JJ Barendregt, Brisbane, 2007), varying the conversion factor between energy consumption change and weight change ${ }^{(32)}$ and the SSB consumption estimates by age and sex.
Sensitivity analysis

In the model energy intake from other types of drinks other than SSB included in our definition was not taken into account. However, an increase in consumption of SSB may be offset by people drinking less of other beverages. This possibility is considered in the sensitivity analysis by assuming that change in other kinds of drinks consumed would be similar to those due to a price reduction of SSB. Deterministic one-way sensitivity analysis was performed to account for the effect of substitution of other beverages. Using previously published price elasticities ${ }^{(40)}$, we calculated the rate of change in BMI resulting from people consuming less milk, diet drinks and unsweetened fruit juice. The number of obese people and change in BMI were computed.

\section{Results}

\section{Change in sugar-sweetened beverage consumption and energy intake}

At baseline, South African adults consumed a daily average of $184(95 \%$ CI 166, 205) $\mathrm{ml} \mathrm{SSB}$, with the $15-24$ years age group drinking the highest amount and those aged 65 years and above drinking the least. The results show that by 2017, South African adults will be consuming approximately $200 \mathrm{ml} \mathrm{SSB}$ /person per d. Because some age groups already have higher baseline consumption they are projected to consume even more than $200 \mathrm{ml} \mathrm{SSB} /$ person per d by 2017 due to the projected $2.4 \%$ growth. The trends in change in energy intake over the years closely mirror those of the change in volume consumed.

Table 1 presents the change in SSB consumption and energy intake over the years accounting for the compounded industry growth. By 2017, the group aged 15-24 years will potentially be drinking an additional $25 \mathrm{ml} \mathrm{SSB}$ / person per d compared with 2012.

Table 1 Change in SSB consumption and energy intake among South African adults aged 15 years and above, by age group, accounting for the compounded industry growth 2013-2017, compared with 2012

\begin{tabular}{|c|c|c|c|c|c|c|c|c|c|c|}
\hline \multirow[b]{2}{*}{ Age group } & \multicolumn{5}{|c|}{ Change in SSB consumption (litres/d) } & \multicolumn{5}{|c|}{ Change in energy intake $(\mathrm{kJ} / \mathrm{d})$} \\
\hline & 2013 & 2014 & 2015 & 2016 & 2017 & 2013 & 2014 & 2015 & 2016 & 2017 \\
\hline $15-19$ years & 0.0050 & 0.0101 & 0.0154 & 0.0208 & 0.0263 & $9 \cdot 01$ & $17 \cdot 57$ & $27 \cdot 78$ & 38.00 & $47 \cdot 24$ \\
\hline $20-24$ years & 0.0050 & 0.0101 & 0.0154 & 0.0208 & 0.0263 & 9.01 & 17.57 & $27 \cdot 78$ & 38.00 & $47 \cdot 24$ \\
\hline $25-29$ years & 0.0048 & 0.0097 & 0.0147 & 0.0198 & 0.0250 & 8.59 & $17 \cdot 70$ & 26.65 & $35 \cdot 20$ & 44.86 \\
\hline 30-34 years & 0.0048 & 0.0097 & 0.0147 & 0.0198 & 0.0250 & 8.59 & $16 \cdot 47$ & $26 \cdot 00$ & 34.72 & 44.41 \\
\hline $35-39$ years & 0.0043 & 0.0088 & 0.0133 & 0.0180 & 0.0227 & $7 \cdot 80$ & 16.03 & 23.04 & 32.00 & 39.73 \\
\hline $40-44$ years & 0.0043 & 0.0088 & 0.0133 & 0.0180 & 0.0227 & $7 \cdot 80$ & 14.46 & $24 \cdot 12$ & 32.52 & 41.34 \\
\hline $45-49$ years & 0.0041 & 0.0083 & 0.0126 & 0.0170 & 0.0215 & $7 \cdot 37$ & 14.57 & 22.65 & 31.00 & 38.51 \\
\hline $50-54$ years & 0.0041 & 0.0083 & 0.0126 & 0.0170 & 0.0215 & $7 \cdot 37$ & 15.02 & 23.46 & 30.04 & 38.08 \\
\hline $55-59$ years & 0.0036 & 0.0072 & 0.0110 & 0.0148 & 0.0187 & 6.42 & $12 \cdot 47$ & 21.60 & $25 \cdot 76$ & 33.09 \\
\hline $60-64$ years & 0.0036 & 0.0072 & 0.0110 & 0.0148 & 0.0187 & $6 \cdot 42$ & $12 \cdot 88$ & 18.93 & $26 \cdot 20$ & 34.19 \\
\hline $65-69$ years & 0.0029 & 0.0058 & 0.0089 & 0.0119 & 0.0151 & $5 \cdot 19$ & 11.49 & $15 \cdot 42$ & $20 \cdot 00$ & $27 \cdot 93$ \\
\hline $70-74$ years & 0.0029 & 0.0058 & 0.0089 & 0.0119 & 0.0151 & $5 \cdot 19$ & 10.45 & $15 \cdot 81$ & 20.72 & $26 \cdot 8 \varepsilon$ \\
\hline $75-79$ years & 0.0029 & 0.0058 & 0.0089 & 0.0119 & 0.0151 & $5 \cdot 19$ & $10 \cdot 39$ & 15.92 & 21.80 & $26 \cdot 98$ \\
\hline$\geq 80$ years & 0.0029 & 0.0058 & 0.0089 & 0.0119 & 0.0151 & $5 \cdot 19$ & $10 \cdot 68$ & $16 \cdot 53$ & 20.75 & $27 \cdot 18$ \\
\hline
\end{tabular}

SSB, sugar-sweetened beverages. 


\section{Change in BMI}

Figure 2 shows the change in BMI units compared with baseline due to the projected SSB industry growth. The results show that by 2017 there is a $0 \cdot 15 \mathrm{BMI}$ unit increase for males and a $0 \cdot 17 \mathrm{BMI}$ unit increase for females due to increased SSB consumption.

\section{Change in obesity}

In Table 2, the proportion of obese men and women with the projected SSB industry growth and accounting for population growth is compared with the proportion of obese men and women when only population growth is considered. The results demonstrate that the proportion of obese men and women increases even without the effect of SSB consumption. There is, however, a greater increase in the proportion of obese adults due to the projected SSB industry growth. The proportion of obese females is higher than males in both scenarios.

Figure 3 presents the additional number of obese people resulting from the $2 \cdot 4 \%$ industry growth alone and not accounting for the effects of population growth on obesity in each year. There are consistently more obese women added than men in all the years. We predict that by 2017 there will be 280000 additional obese adults due to increased SSB consumption. We also predict the $2.4 \% \mathrm{SSB}$

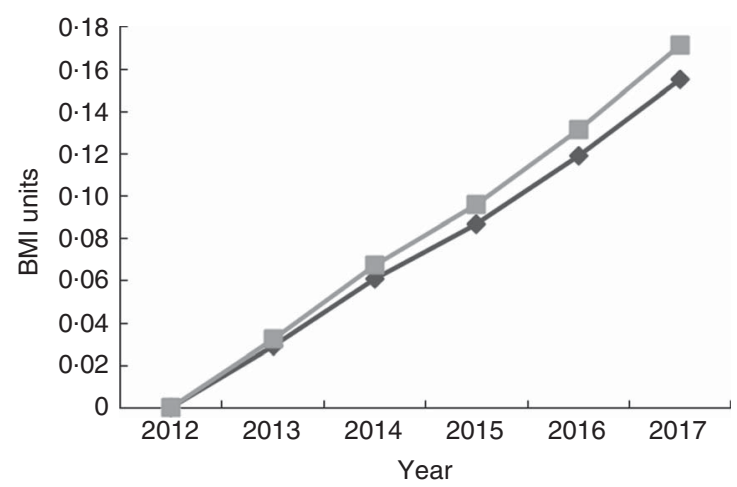

Fig. 2 Cumulative change in BMI in South African adults aged 15 years and above (_- males; _ $\ldots$, females) due only to the growth in the SSB industry, 2012-2017 (SSB, sugarsweetened beverages) industry growth will result in approximately 21000 additional obese men and about 35000 additional obese women year on year. Figure 3 shows that although the additional number of obese adults in the first two modelled years is relatively modest, at approximately 48000 in 2013 and 100000 in 2014, the numbers increase exponentially by 2017 due to the compounding effect.

The NIDS data show that in 2012, the baseline year, there were 2.03 million obese men and 5.87 million obese women in South Africa. When both the $2.4 \%$ industry growth and population growth are accounted for, there may be an additional 1.29 million obese adults by 2017 (Table 3). Table 3 also shows that by 2017 there will be $5.2 \%$ additional obese men and $3.0 \%$ additional obese women due to the SSB industry growth alone.

\section{Sensitivity analysis}

The model was run assuming substitution with other beverages based on previously described price elasticities (Table 4$)^{(40)}$. The results of the sensitivity analysis show that if the assumption is included that people who drink more SSB will drink slightly lower quantities of other beverages, the increase in the number of obese adults from 2012 to 2017 is only marginally lower than when substitution is not accounted for.

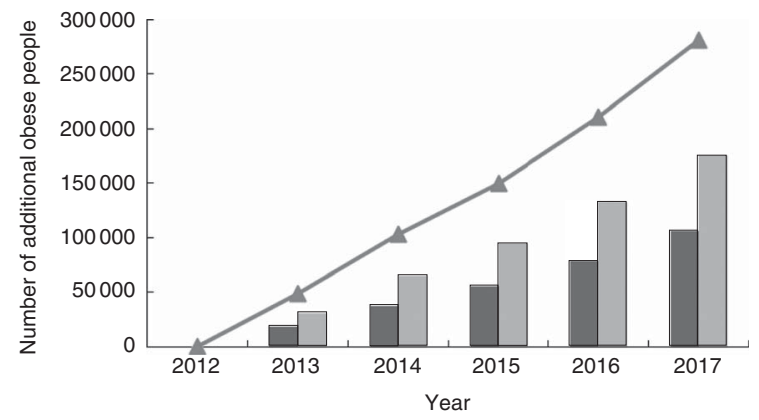

Fig. 3 Increase in number of obese South African adults aged 15 years and above $\left(\square\right.$, males; $\square$, females; $\_-$, all) due only to the growth in the SSB industry, 2012-2017 (SSB, sugarsweetened beverages)

Table 2 Comparison of the proportion of obese South African adults aged 15 years and above, by sex, with and without SSB industry growth and accounting for population growth

\begin{tabular}{|c|c|c|c|c|c|c|c|c|}
\hline \multirow[b]{3}{*}{ Year } & \multicolumn{4}{|c|}{$0 \%$ industry growth } & \multicolumn{4}{|c|}{$2.4 \%$ industry growth } \\
\hline & \multicolumn{2}{|c|}{ Males } & \multicolumn{2}{|c|}{ Females } & \multicolumn{2}{|c|}{ Males } & \multicolumn{2}{|c|}{ Females } \\
\hline & $\%$ & $95 \% \mathrm{Cl}$ & $\%$ & $95 \% \mathrm{Cl}$ & $\%$ & $95 \% \mathrm{Cl}$ & $\%$ & $95 \% \mathrm{Cl}$ \\
\hline 2012 & 13.47 & $13.45,13.48$ & $35 \cdot 47$ & $35.44,35.49$ & 13.47 & $13.45,13.48$ & $35 \cdot 47$ & $35.44,35.49$ \\
\hline 2013 & 13.51 & $13.51,13.51$ & $35 \cdot 51$ & $35.51,35.51$ & 13.62 & $13.61,13.62$ & 35.69 & $35.67,35.70$ \\
\hline 2014 & 13.56 & $13 \cdot 29,13 \cdot 82$ & 35.54 & $35.13,35 \cdot 94$ & $13 \cdot 80$ & $13.54,14.04$ & 35.92 & $35.51,36.32$ \\
\hline 2015 & 13.63 & $13 \cdot 36,13 \cdot 91$ & 35.62 & $35.18,36.05$ & 13.97 & $13 \cdot 72,14 \cdot 22$ & $36 \cdot 15$ & $35.75,36.54$ \\
\hline 2016 & $13 \cdot 70$ & $13.44,13.97$ & 35.69 & $35 \cdot 30,36 \cdot 12$ & 14.17 & $13.92,14.45$ & $36 \cdot 42$ & $36.04,36.82$ \\
\hline 2017 & $13 \cdot 77$ & $13.49,14.02$ & $35 \cdot 77$ & $35 \cdot 33,36 \cdot 17$ & 14.39 & $14 \cdot 13,14.62$ & 36.72 & $36 \cdot 33,37 \cdot 13$ \\
\hline
\end{tabular}

SSB, sugar-sweetened beverages. 
Table 3 Projected total numbers of obese South African adults aged 15 years and above, and proportion of additional obese adults each year, by sex and overall

\begin{tabular}{|c|c|c|c|c|c|c|c|c|c|}
\hline \multirow[b]{2}{*}{ Year } & \multicolumn{3}{|c|}{ Males } & \multicolumn{3}{|c|}{ Females } & \multicolumn{3}{|c|}{ All } \\
\hline & $\begin{array}{c}\text { Number } \\
\text { obese } \\
\text { (millions) }^{*}\end{array}$ & $95 \% \mathrm{Cl}$ & $\begin{array}{c}\text { Proportion } \\
\text { additional obese } \\
(\%) \dagger\end{array}$ & $\begin{array}{c}\text { Number } \\
\text { obese } \\
\text { (millions) }^{*}\end{array}$ & $95 \% \mathrm{Cl}$ & $\begin{array}{c}\text { Proportion } \\
\text { additional obese } \\
(\%) \dagger\end{array}$ & $\begin{array}{c}\text { Number } \\
\text { obese } \\
\text { (millions)* }\end{array}$ & $95 \% \mathrm{Cl}$ & $\begin{array}{c}\text { Proportion } \\
\text { additional obese } \\
(\%) \dagger\end{array}$ \\
\hline 2012 & \multicolumn{2}{|c|}{2.03} & 0 & \multicolumn{2}{|c|}{5.87} & 0 & \multicolumn{2}{|c|}{7.90} & 0 \\
\hline 2013 & $2 \cdot 11$ & $2 \cdot 11,2 \cdot 11$ & 0.9 & 6.03 & $6.02,6.03$ & 0.5 & $8 \cdot 13$ & $8.13,8.14$ & 0.6 \\
\hline 2014 & $2 \cdot 19$ & $2 \cdot 15,2 \cdot 23$ & $1 \cdot 8$ & $6 \cdot 19$ & $6 \cdot 12,6 \cdot 26$ & $1 \cdot 1$ & $8 \cdot 38$ & $8.27,8.49$ & 1.3 \\
\hline 2015 & $2 \cdot 27$ & $2 \cdot 23,2 \cdot 31$ & $2 \cdot 7$ & $6 \cdot 36$ & $6 \cdot 29,6 \cdot 43$ & 1.6 & 8.63 & $8 \cdot 52,8 \cdot 74$ & 1.9 \\
\hline 2016 & $2 \cdot 36$ & $2 \cdot 32,2 \cdot 41$ & 3.9 & 6.55 & $6 \cdot 48,6 \cdot 62$ & $2 \cdot 2$ & 8.90 & $8.80,9.02$ & $2 \cdot 7$ \\
\hline 2017 & 2.45 & $2 \cdot 41,2 \cdot 50$ & $5 \cdot 2$ & $6 \cdot 74$ & $6 \cdot 67,6 \cdot 82$ & 3.0 & $9 \cdot 19$ & $9 \cdot 07,9.31$ & $3 \cdot 6$ \\
\hline
\end{tabular}

SSB, sugar-sweetened beverages.

${ }^{*}$ Due to population growth and SSB industry growth.

†Due to SSB industry growth relative to baseline (2012).

Table 4 Sensitivity analysis on decreased consumption of milk, diet drinks and fruit juice based on price elasticities

\begin{tabular}{cccc}
\hline Year & $\begin{array}{c}\text { Number of additional obese } \\
\text { adults (2.4\% growth only; } \\
\text { thousands) }\end{array}$ & $\begin{array}{c}\text { Number of } \\
\text { obese males } \\
\text { (millions) }\end{array}$ & $\begin{array}{c}\text { Number of } \\
\text { obese females } \\
\text { (millions) }\end{array}$ \\
\hline 2012 & 0 & 2.09 & 6.00 \\
2013 & 31 & $2 \cdot 10$ & 6.02 \\
2014 & 64 & $2 \cdot 17$ & 6.17 \\
2015 & 100 & 2.25 & 6.33 \\
2016 & 128 & 2.33 & 6.49 \\
2017 & 276 & 2.34 & 6.57 \\
\hline
\end{tabular}

\section{Discussion}

We estimate that by 2017 there will be a $16 \%$ increase in the number of obese adults in South Africa due to both population growth and the SSB industry growth, putting the total at $9 \cdot 2$ million. Over a period of 5 years there will be an additional 1.29 million obese adults in South Africa, 280000 of which will be due to increased SSB consumption. In other words, there will be 35000 additional obese women and 21000 additional obese men year on year due to increased SSB consumption alone. These findings demonstrate that more than a quarter of the projected increase in obesity by 2017 will be due to SSB consumption. These results are comparable to other studies which show that $20 \%$ of the increase in BMI over the last three decades in the USA is attributable to SSB consumption ${ }^{(11)}$. Another study in India showed that overweight prevalence would increase by $11 \%$ over 9 years when taking into account the curvilinear rise of marketing model projections for SSB consumption ${ }^{(41)}$.

By 2017 South African adults will potentially be consuming an average of $200 \mathrm{ml}$ of SSB per person daily, the equivalent of 6 teaspoons of sugar. With this amount of sugar consumption from SSB alone there is little margin for the consumption of other products with added or hidden sugars and to simultaneously remain below the WHO recommended sugar limit of $10 \%$ of daily energy ${ }^{(42)}$. These results show that if effective interventions are not implemented SSB consumption will increase and South Africa's obesity burden will continue to grow.

The total increase in SSB consumption and obesity is not expected to occur evenly across LSM (SES) groups. Although we were unable to model the impact of increased consumption by LSM group, SSB consumption in South Africa is currently greater in higher-income groups ${ }^{(18)}$. According to SABMiller figures, per capita consumption of Coca-Cola in LSM 7-10 (the four highest SES groups) is estimated at $292 \mathrm{ml} / \mathrm{d}$, compared with $188 \mathrm{ml} / \mathrm{d}$ in LSM 4-6 (medium SES groups) and $122 \mathrm{ml} / \mathrm{d}$ in LSM 1-3 (lowest SES groups $)^{(18)}$. SANHANES data show an average SSB consumption of $186 \mathrm{ml} / \mathrm{d}$ in urban informal areas and an average of $161 \mathrm{ml} / \mathrm{d}$ in rural informal areas ${ }^{(2)}$. In the future, SSB consumption trends will probably change with consumption becoming higher in lower-income groups (as has occurred in other countries like Mexico and the USA) ${ }^{(18,43)}$. The largest soft drink franchise in the country has outlined its future growth strategy and has identified LSM 1-6 as its main market opportunity, with a specific focus on LSM $1-3^{(18)}$. This is the poorest sector, which currently has the lowest per capita consumption. It has been suggested by industry that lessons learned in Mexico, where soft drink consumption is highest globally, should be applied in South Africa ${ }^{(18)}$. The SABMiller growth strategy indicates that this will include improving service levels and increasing delivery frequency of products, growing the number of outlets to improve penetration while ensuring that existing outlets are serviced accordingly, and increasing the number of coolers (storage for SSB) per outlet, in addition to building stronger brand loyalty ${ }^{(18)}$. In 2011 this growth strategy was implemented in Tembisa, an informal settlement near Johannesburg comprising 1.3 million people. The result was a tripling of the number of outlets to eighteen per 10000 people and a doubling of the number of coolers to sixteen per 10000 people. This generated a $7.5 \%$ volume growth in Coca-Cola products between 2011 and $2012^{(18)}$. The comparison in the growth strategy between South Africa and Mexico suggests an intention to increase per capita consumption of soft drinks in South 
Africa by three times within LSM 1-3. The growth strategy as implemented in Tembisa will likely be extended and will occur alongside marketing and advertising strategies to further develop brand loyalty. This in turn will result in a significant increase in the number of obese people in these groups, putting them at greater risk for NCD and perpetuating the cycle of poverty and ill-health.

\section{Study strengths and limitations}

The present study is the first in sub-Saharan Africa to assess the impact of increased SSB consumption on future obesity trends. The study has several strengths. First, we were able to use nationally representative data from South Africa to estimate baseline consumption of different drinks and the baseline prevalence of obesity. This increases the generalizability of our results to all South African adults and potentially to other populations in low- and middleincome countries similar to South Africa. In addition, the height and weight from the survey were measured, which should allow for a high degree of accuracy of the BMI estimates. A limitation, however, is that our projections of obesity do not account for the BMI trend in South Africa and may be an underestimate. In addition, BMI is an imperfect measure of obesity as it does not always accurately take into account body fat ${ }^{(44)}$. This can lead to either overestimations or underestimations of obesity. In our study, we would not have been able to measure obesity in the entire adult population without using BMI.

We used the SANHANES-1 to estimate baseline consumption levels of different drinks. However, comparison with soft drink sales suggests that these estimates may have been too low. Euromonitor data show 2012 soft drink sales totalling 4.75 million litres, an average of $254 \mathrm{ml} /$ person per $d$, which is higher than the SANHANES estimate of $184 \mathrm{ml}$. This may be due to the fact that Euromonitor includes a broader category of soft drinks than those included as SSB by SANHANES, or it may be the result of recall or reporting bias. There is further evidence that SANHANES figures may be an underestimate when compared with SABMiller figures; the latter show annual per capita consumption of all Coca-Cola products at 67 litres in $2012^{(18)}$. These products account for about $60 \%$ of the (off-trade) soft drinks market, so the average South African is potentially consuming approximately $315 \mathrm{ml}$ of SSB daily. The SANHANES data are the only source that is subdivided by age group and was therefore used for our model, bearing in mind the likely underestimation. At the time of the modelling, figures from the most recent Euromonitor report were used to project increase in SSB consumption. However, this report has subsequently been updated and shows that soft drink sales are projected to grow by $3.9 \%$ per year between 2004 and $2019^{(45)}$. Further, we used the total $2 \cdot 4 \%$ industry growth across all age groups to project future consumption and this may have resulted in an underestimate of projected consumption in some age groups and an overestimate in others.

\section{Policy implications}

The South African nutrition policy context has developed from one focused solely on undernutrition to one that also seeks to address the growing NCD epidemic. The South African Strategic Plan for Prevention and Control of NonCommunicable Diseases 2013-2017 ${ }^{(6)}$ identifies several cost-effective interventions for addressing obesity, one of which is a tax on unhealthy products ${ }^{(6)}$. Although there is good evidence to suggest that an SSB tax is an effective intervention in reducing consumption, a package of population-level interventions is essential to ensure maximal impact. Other potential, concurrent measures include food advertising regulations, easy-to-understand food labelling, worksite interventions and school-based interventions $^{(6)}$. Government could also subsidize healthy products. Ideally this should be accompanied by strong public campaigns about the health implications of sugar and of excessive SSB consumption. The Strategic Plan acknowledges the need for this type of multi-pronged response ${ }^{(6)}$; however, the progress in terms of implementation seems to be protracted as specific regulations are yet to be passed. This, despite the recognition in the Foreword to the Plan that 'without strong and innovative interventions now, we will not only subvert government's goal of a long and health life for all, but our health services could in the future become overwhelmed with patients requiring acute as well as long term health care ${ }^{,(6)}$. Indeed, some challenges may be difficult to overcome, especially those surrounding vested interests ${ }^{(46)}$, but in the absence of effective preventive measures SSB consumption will continue to grow. This will lead to a greater burden of obesity, as demonstrated by the results presented herein.

Currently, consumers are persuaded to make unhealthy choices through the use of tactical marketing techniques and strategic placement and availability of high-energy products $^{(16)}$. It is the responsibility of the government to protect the health of its population by levelling the playing field through interventions that nudge people to make healthier and more sustainable choices. In the absence of immediate implementation of the cost-effective interventions identified in the Strategic Plan, the target of $10 \%$ reduction in obesity by 2020 will likely be difficult to achieve and the health systems in South Africa will confront serious challenges in tackling obesity and related NCD.

\section{Acknowledgements}

Acknowledgements: The authors thank Jan Barendregt for assistance with the Ersatz software. They also acknowledge Dr Celeste Naude for her assistance in calculation of the energy density of SSB. Financial support: Funding was provided by the IDRC - International Development Research Centre, Canada (grant fund number PROP020911E). PRICELESS SA is funded by the South African Medical Research Council (grant fund number 
D1305910-01). The funders had no role in the design, analysis or writing of this article. Conflict of interest: None. Authorship: A.T. and M.M. contributed equally to this study. All authors were responsible for the study concept and design. M.M. performed the modelling. L.J.V. supervised the modelling. A.T. performed the analysis. A.T. and M.M. drafted the manuscript. K.J.H., L.J.V., L.C. and D.L. reviewed and provided comments on the manuscript. Ethics of human subject participation: There are no ethical concerns with this paper; ethics review board approval was not required as no human subjects were involved and only secondary data were used.

\section{References}

1. Department of Health, Medical Research Council \& OrcMacro (2007) South Africa Demographic and Health Survey 2003. Pretoria: Department of Health.

2. Shisana O, Labadarios D, Rehle T et al. (2013) South African National Health and Nutrition Examination Survey (SANHANES-1). Cape Town: HSRC Press.

3. Igumbor EU, Sanders D, Puoane TR et al. (2012) 'Big food', the consumer food environment, health, and the policy response in South Africa. PLoS Med 9, e1001253.

4. Malaza A, Mossong J, Barnighausen T et al. (2012) Hypertension and obesity in adults living in a high HIV prevalence rural area in South Africa. PLoS One 7, e47761.

5. Joubert J, Norman R, Bradshaw D et al. (2007) Estimating the burden of disease attributable to excess body weight in South Africa in 2000. S Afr Med J 97, 683-690.

6. National Department of Health (2013) Strategic Plan for the Prevention and Control of Non-Communicable Diseases 2013-17. Pretoria: NDOH.

7. Vartanian LR, Schwartz MB \& Brownell KD (2007) Effects of soft drink consumption on nutrition and health: a systematic review and meta-analysis. Am J Public Health 97, 667-675.

8. Sturm R, An R, Maroba J et al. (2013) The effects of obesity, smoking, and excessive alcohol intake on healthcare expenditure in a comprehensive medical scheme. $S$ Afr Med $J$ 103, 840-844.

9. Tugendhaft A \& Hofman K (2014) Empowering healthy food and beverage choices in the workplace. Occup Health $S$ Afr 22, 6-8.

10. Hu FB \& Malik VS (2010) Sugar-sweetened beverages and risk of obesity and type 2 diabetes: epidemiologic evidence. Physiol Behav 100, 47-54.

11. Woodward-Lopez G, Kao J \& Ritchie L (2011) To what extent have sweetened beverages contributed to the obesity epidemic? Public Health Nutr 14, 499-509.

12. Te Morenga L, Mallard S \& Mann J (2013) Dietary sugars and body weight: systematic review and meta-analyses of randomised controlled trials and cohort studies. BMJ 346, e7492.

13. Babey SH, Jones M, Yu H et al. (2009) Bubbling over: soda consumption and its link to obesity in California. Policy Brief UCLA Cent Health Policy Res issue PB2009-05, 1-8.

14. Malik VS \& Hu FB (2012) Sweeteners and risk of obesity and type 2 diabetes: the role of sugar-sweetened beverages. Curr Diab Rep 12, 195-203.

15. Finmark Trust \& FinScope SA (2013) FinScope SA 2013 Consumer Survey. http://www.finmark.org.za/wp-content/ uploads/pubs/Pres_FSSA_2013_excluding-videos2.pdf (accessed August 2014).

16. Freudenberg N (2014) Lethal but Legal: Corporations, Consumption, and Protecting Public Health. New York: Oxford University Press.
17. Times Media Division Ad Room (2013) Sunday Times top brands awards 2013. http://www.tmadroom.co.za/surveys-1/ i-am-brand (accessed July 2014).

18. Adami N, Ustas J, Penhale I et al. (2012) SABMiller plc Quarterly Divisional Seminar Series South Africa. London: SABMIller plc.

19. The Coca-Cola Company (2013) Per capita consumption of company beverage products. http://www.coca-colacompany. com/annual-review/2012/pdf/2012-per-capita-consumption.pdf (accessed November 2013)

20. Mackay A \& Blyth D (2014) Brands that have made it in the new South Africa. http://www.ywood.co.za/thinking/ articles/brands-that-have-made-it-in-the-new-south-africa. aspx (accessed May 2014).

21. United Nations (2011) Non-communicable diseases deemed development challenge of 'epidemic proportions' in political declaration adopted during landmark General Assembly Summit. http://www.un.org/press/en/2011/ga11138. doc.htm (accessed November 2014).

22. Dodds C (2013) Minister of Health goes sour on sugar. In The Saturday Star. South Africa: Independent News and Media.

23. European Public Health Alliance (2012) Food taxation in Europe: evolution of the legislation. http://www.epha.org/ 4814 (accessed March 2015)

24. Obesity Policy Coalition (2015) Aussies give green light on tax for sugar-filled drinks to curb obesity epidemic. http:// www.opc.org.au/latestnews/mediareleases/pages/aussiesgive-green-light-on-tax-for-sugar-filled-drinks.aspx-.VYsAM ROqqko (accessed June 2015).

25. Cheney C (2011) Battling the couch potatoes: Hungary introduces 'fat tax'. http://www.spiegel.de/international/ europe/battling-the-couch-potatoes-hungary-introduces-fattax-a-783862.html (accessed June 2014).

26. Spiegel Online International (2011) French 'cola tax' approved: Paris vows to fight deficit and obesity. http://www.spiegel.de/ international/europe/french-cola-tax-approved-paris-vows-tofight-deficit-and-obesity-a-806194.html (accessed May 2014).

27. UNESDA (2010) Why Discriminatory Taxes Don't Work. Brussels: UNESDA.

28. Frizell S (2014) Nation's first soda tax passed in California city. http://time.com/3558281/soda-tax-berkeley/ (accessed December 2014).

29. Mexican National Institute of Public Health (2014) Preliminary results of a one peso tax on sugar sweetened beverages in Mexico. http://www.insp.mx/epppo/blog/ preliminares-bebidas-azucaradas.html (accessed June 2015).

30. Manyema M, Veerman L, Chola L et al. (2014) The potential impact of a $20 \%$ tax on sugar-sweetened beverages on obesity in South African adults: a mathematical model. PLOS One 9, e105287.

31. Euromonitor International (2013) Soft Drinks in South Africa: Industry Overview. London: Euromonitor International.

32. Swinburn BA, Sacks G, Lo SK et al. (2009) Estimating the changes in energy flux that characterize the rise in obesity prevalence. Am J Clin Nutr 89, 1723-1728.

33. Southern Africa Labour and Development Research Unit (2013) National Income Dynamics Study 2012, Wave 3. Cape Town: DataFirst.

34. Leibbtandt M, Woolard I \& de Villiers L (2009) Methodology: Report on NIDS Wave 1. NIDS Technical Paper no. 1. Cape TOwn: SALDRU.

35. Brown M, Daniels RC, De Villiers L et al., (editors) (2012) National Income Dynamics Study. Wave 2 User ManualUpdated. Cape Town: SALDRU.

36. De Villiers L, Brown M, Woolard I et al., (editors) (2013) National Income Dynamics Study. Wave 3 User Manual. Cape Town: SALDRU.

37. Statistics South Africa (2014) Quarterly Labour Force Survey, Quarter 1, 2014: Appendix 1, no. P0211. Pretoria: Statistics South Africa. 
38. Wolmarans P, Danster N, Dalton A et al. (2010) Condensed Food Composition Tables for South Africa. South Africa: South African Food Data System, South Africa Medical Research Council.

39. Rose G \& Day S (1990) The population mean predicts the number of deviant individuals. BMJ 301, 1031-1034.

40. Cabrera Escobar MA, Veerman J, Tollman SM et al. (213) Evidence that a tax on sugar sweetened beverages reduces the obesity rate: a meta-analysis. BMC Public Health 13, 1072.

41. Basu S, Vellakkal S, Agrawal S et al. (2014) Averting obesity and type 2 diabetes in India through sugar-sweetened beverage taxation: an economic-epidemiologic modeling study. PLOS Med 11, e1001582.
42. World Health Organization (2015) Sugar Intake for Adults and Children: Guideline. Geneva: WHO.

43. Han E \& Powell LM (2013) Consumption patterns of sugarsweetened beverages in the United States. J Acad Nutr Diet 113, 43-53.

44. Hall DM \& Cole TJ (2006) What use is the BMI? Arch Dis Child 91, 283-286.

45. Euromonitor International (2014) Soft Drinks in South Africa: Industry Overview. London: Euromonitor International.

46. Myers A, Fig D, Tugendhaft A et al. (2015) Sugar and health in South Africa: potential challenges to leveraging policy change. Global Public Health (Epublication ahead of print version). 